Netzwerk Demenz ausgezeichnet

\section{Altenhilfepreis in Sachsen}

— Der Sächsische Altershilfepreis 2016 geht an das Chemnitzer Projekt "DemenzNetz_C“. Die Initiative vertritt die Interessen von demenzkranken Menschen sowie deren Angehörigen und spannt ein trägerübergreifendes Netzwerk zum Thema Demenz in der Stadt. Die Auszeichnung ist mit 5.000 Euro dotiert. Sachsens Sozialministerin Barbara Klepsch (CDU) betonte die Bedeutung regionalen Engagements. „Wir wollen ein selbstbestimmtes und würdevolles Leben im Alter sowie bei Pflegebedürftigkeit ermöglichen", so Klepsch. Mit dem Preis werden alle zwei Jahre Projekte ausgezeichnet, die Selbstständigkeit und Entscheidungsfähigkeit älterer Menschen fördern.

www.sms.sachsen.de
Pilot-Studie "Reha-Biograf"

\section{Langzeiterkrankte Pflegekräfte: Was läuft schief?}

— Überdurchschnittlich viele Pflegefachkräfte werden im Laufe ihres Berufslebens selbst langzeitkrank, etliche von innen finden sich in der beruflichen Rehabilitation wieder. Der "Reha-Biograf" des Lehrstuhls für Pflegewissenschaft der Philosophisch-Theologischen Hochschule Vallendar (PTHV) beschreibt erstmals ein dreiphasiges Modell zu Ursachen und möglichen Interventionszeitpunkten. Auf Grundlage der Studie können Maßnahmen der Prävention und der Rehabilitation entwickelt werden, die sowohl das krankheitsbedingte Ausscheiden verhindern als auch den Wiedereinstieg fördern können.

www.pthv.de

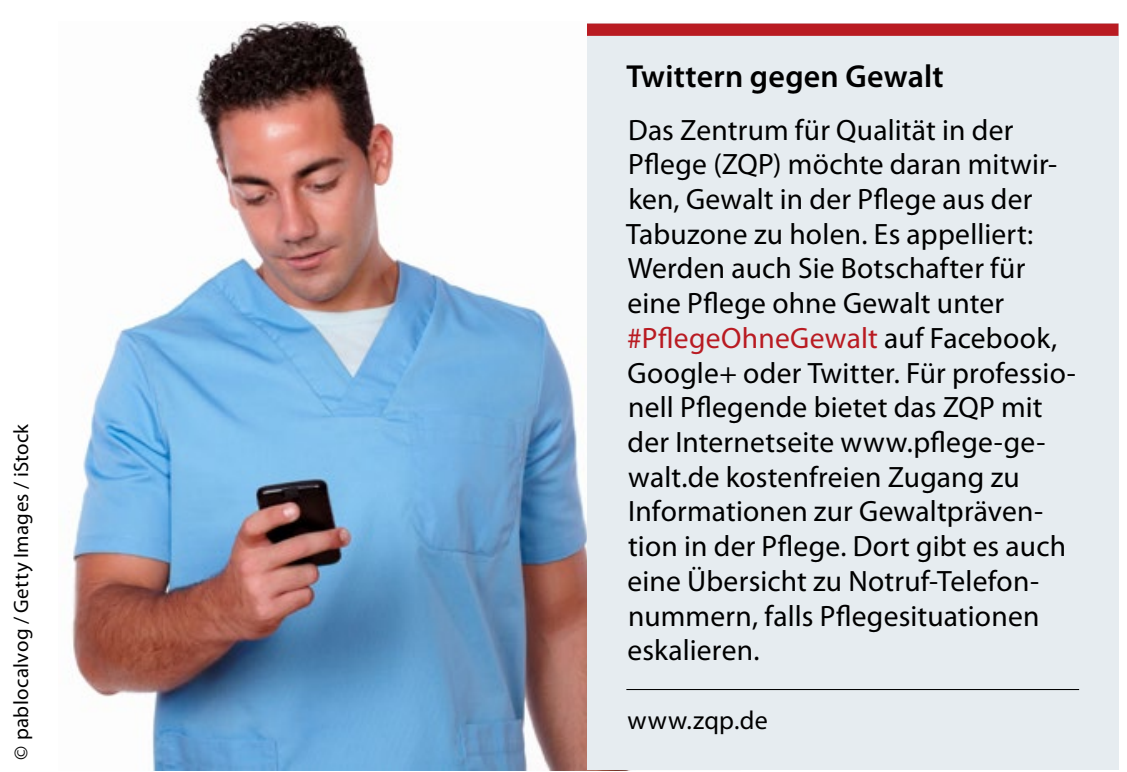

Ambulante Hospizdienste und Kliniken in Bayern

\title{
Huml fordert bessere Kooperation
}

— Bayerns Gesundheits- und Pflegeministerin Melanie Huml setzt auf eine verstärkte Zusammenarbeit zwischen ambulanten Hospizdiensten und Krankenhäusern. Das bayerische Gesundheitsministerium informierte in einem Schreiben die Krankenhausträger über die - auf Grundlage des Hospiz- und Palliativgesetzes - in Kraft getretene Rahmenvereinbarung zur ambulan- ten Hospizarbeit. Nach den neuen Regelungen erhalten ambulante Hospizdienste nicht nur für die ehrenamtliche Sterbebegleitung im häuslichen Umfeld einen Zuschuss durch die Krankenkassen, sondern künftig auch, wenn die ehrenamtliche Sterbebegleitung in Kliniken erfolgt. Voraussetzung dafür ist, dass die Krankenhausträger den ambulanten Hospizdienst be-

\section{Wohnen | Gesundheit | Arbeit Demografiekongress}

— Weil die Zukunftsfähigkeit Deutschlands maßgeblich von einer erfolgreichen Gestaltung des demografischen Wandels abhängt, steht der Demografiekongress 2016 ganz im Zeichen des Zuzugs von Flüchtlingen nach Deutschland: Verändert sich durch die Zuwanderung die demografische Situation? Wie gelingt die soziale und arbeitsmarktliche Eingliederung von Flüchtlingen? Kann ausreichend (preiswerter) Wohnraum in Deutschland geschaffen werden? Diesen und anderen Fragen will man am 1. und 2. September in Berlin auf den Grund gehen.

www.der-demografiekongress.de auftragt haben. Möglich sei ein genereller Auftrag für eine regelmäßige Zusammenarbeit. „Ziel ist, dass alle Betroffenen und Angehörigen die erforderliche Sterbebegleitung erfahren", so die Ministerin. Derzeit gibt es in Bayern über 140 Hospizvereine mit rund 26.000 Vereinsmitgliedern. Rund 6.900 aktive ehrenamtliche Helfer begleiten schwerstkranke und sterbende Menschen.

www.stmgp.bayern.de 